\title{
DUALISME IDENTITAS PERANAKAN ARAB DI KAMPUNG ARAB GRESIK
}

\author{
Fikri Mahzumi \\ Universitas Islam Negeri Sunan Ampel Surabaya, Indonesia \\ E-mail: fikrimuz@gmail.com
}

\begin{abstract}
The article attempts to ethnographically describe struggle of identity among the Arabian offspring in Indonesia in the post Reformation Era. As the descendants of the Hadrami migrants who have born in Indonesia, the Arabian offspring deal with two interrelated identities; between their responsibility to preserve the traditions of their ancestors and becoming a wholly recognized citizen of Indonesia. The debate about nationalism among the Arabian-Hadrami people appeared prior to Indonesia's independence revolution. Anti-colonialism movements in this period had raised solidarity and solidity among the Indonesian people. This situation indubitably urged the Arabian-Hadrami people to reformulate their concept of nationalism. As a part of their nationality commitments, the Arabian Hadrami people have subsequently founded two organizations, i.e. Jamiat Khair (est. 1901) and Jamiyat al-Islah wal-Irsyad al-Arabiyah (est. 1915). In 1934, Abdurrahman Baswedan also founded Persatuan Arab Indonesia, which played pivotal role in cultivating Indonesian nationalism among the Arabian-Hadrami people. In the post Reformation Era, however, the issue of nationalism of the Arabian offspring has never been re-discussed. Employing ethnographical approach this study observes the ways the Arabian offspring, in Kampung Arab (the Arabic Town) in Gresik, compromise and negotiate with two challenges they face at once; as the heirs of Hadrami traditions and as a part of Indonesian citizens.
\end{abstract}

Keywords: Arabian offspring; identity; nationalism.

\section{Pendahuluan}

Sebagai keturunan migran dari Hadramaut yang lahir di Indonesia, Peranakan Arab atau disebut muwallad dihadapkan pada dua sisi identitas yang saling berpunggungan; antara tanggung jawab mewarisi 
tradisi salaf (leluhur) Hadrami dan tuntutan menjadi warga negara Indonesia seutuhnya. Kondisi ini kemudian menciptakan ruang negosiasi bagi Peranakan Arab untuk menjaga keduannya agar seimbang dan saling mengisi. Pada titik ini, kreativitas dalam beradaptasi sangat dibutuhkan sekaligus menentukan kesuksesan Peranakan Arab menjawab tantangan nasionalisme kekinian untuk konteks Indonesia tanpa kehilangan akar tradisi yang telah lama diwariskan oleh leluhur mereka. Selain itu, kemampuan adaptasi tersebut akan memupus eksklusivitas yang menjadi sekat primordial bagi Peranakan Arab sehingga membedakan mereka dari warga negara Indonesia secara umum. Proses adaptasi Peranakan Arab untuk menjadi bagian dari nasionalisme Indonesia memiliki sejarah panjang dan penuh dinamika. Menurut Van der Kroef (1954)—yang dikutip oleh Abdul Rachman Patji (1991)—bahwa pergulatan nasionalisme orang-orang Arab-Hadrami muncul menjelang revolusi kemerdekaan. Kelahiran nasionalisme Indonesia pada 1908 memaksa koloni migran termasuk orang-orang Arab-Hadrami merumuskan konsep nasionalisme baru sebagi bukti komitmen kebangsaan dan kecintaan terhadap tanah air. ${ }^{1}$

Proses menuju nasionalisme Indonesia di kalangan orang-orang Arab-Hadrami memang tidak sederhana. Pergulatan menuju nasionalisme Indonesia itu dapat dilihat melalui dinamika internal dari komunitas ini ketika bergabung dalam Sarekat Dagang Islam yang didirikan pada 1909 yang kemudian berubah nama menjadi Sarekat Islam (SI) pada 1911. Pendirian organisisi Jamiat Kheir pada 1901 yang lebih awal dari pendirian Sarekat Dagang Islam dan Jam'iyat alIslah wa al-Irsyad al-Arabiyah pada 1914 yang didirikan setelah Sarekat Islam, menjadi bukti lain upaya orang-orang Arab-Hadrami merumuskan nasionalisme antara setia kepada Hadramaut atau bersama-sama dengan masyarakat pribumi mewujudkan cita-cita Indonesia. Gerakan nasionalisme Indonesia di kalangan orang-orang Arab-Hadrami semakin matang ketika A.R. Baswedan mendirikan Persatuan Arab Indonesia (PAI) pada 1934. Organisasi yang sempat menjadi sebuah partai pada 1940 hingga dibubarkan di era pendudukan Jepang sangat berkontribusi dalam memupuk semangat nasionalisme bagi orang-orang Arab-Hadrami terutama peranakan.

${ }^{1}$ Justus M. Van der Kroef, Indonesia in the Modern World. Part I (Bandung: Masa Baru, 1954) dalam Abdul Rachman Patji, "The Arabs of Surabaya: A Study of Sociocultural Integration” (Tesis--Australian National University, 1991). 
Puncak dari pembuktiaan nasionalisme Indonesia adalah ketika dilaksanakan Sumpah Pemuda keturunan Arab pada konferensi yang dilaksanakan di Semarang sekaligus menandai berdirinya organisasi PAI.

Natalie Mobini-Kesheh (1996) menyebut awal abad 19 merupakan momentum kebangkitan nasionalisme. Mengutip dari Takashi Shiaishi (1990) pada era itu terjadi transformasi politik, sosial, dan keagamaan bagi koloni migran di Hindia Belanda yang ditandai dengan kemunculan ide-ide baru dan organisasi-organisasi modern. Momentum tersebut dikenal dengan istilah "kebangkitan nasionalisme" (nasionalism awakening atau nahdat al-watanyah). Bagi orang-orang Arab-Hadrami, kebangkitan nasionalisme itu ditandai dengan semangat nabdah Hadramiyah yang mendorong mereka mendirikan lembaga-lembaga berupa organisasi sosial (jam'iyah), sekolah modern (madrasah), dan koran (jaridab). ${ }^{2}$ Nasionalisme orangorang Arab-Hadrami pada awalnya masih mempertahankan Hadramaut sebagai tanah air. Hal itulah yang menyebabkan mereka terjebak pada ambiguitas dan perdebatan tentang nasionalisme hingga muncullah gerakan dari Peranakan Arab modernis seperti AR. Baswedan yang menyerukan nasionalisme Indonesia. Pascakemerdekaan, orang-orang Arab-Hadrami menjadi bagian dari Indonesia. Banyak dari tokoh-tokoh Peranakan Arab yang terlibat dalam mengisi pembangunan di republik ini. Nama seperti Muhammad Quraish Syihab, Anies Baswedan, Rizieq Syihab dan Muhammad Luthfi b. Yahya adalah contoh tokoh dari golongan ini yang populer di era sekarang. ${ }^{3}$

Berawal dari deskripsi singkat di atas, artikel ini diarahkan untuk melakukan kajian etnografi tentang pergumulan dwi identitas yang dialami oleh Peranakan Arab di Kampung Arab Gresik. Dengan melihat sejarah nasionalisme di kalangan orang-orang Arab-Hadrami dan tantangan nasionalisme di Indonesia dewasa ini, ikhtiar akademik ini berupaya mengukur kembali konsistensi nasionalisme Peranakan Arab, khususnya di kalangan mudanya. Alasan mendasar menentukan Gresik sebagai wilayah penelitian lebih karena pertimbangan

${ }^{2}$ N. Mobini-Kesheh, "The Arab Periodicals of the Netherlands East Indies, 19141942", Journal of Humanities and Social Sciences of Southeast Asia, Vol. 156, No. 2 (1996), 236-256.

${ }^{3}$ Sumanto Al Qurtuby, “Arabs and 'Indo-Arabs' in Indonesia: Historical Dynamics, Social Relations and Contemporary Changes", International Journal of Asia Pacific Studies, Vol. 13, No. 2 (2017), 45-72. 
akademik. Berdasarkan catatan sejarah tentang koloni Arab-Hadrami, Gresik merupakan tujuan migrasi awal dari koloni Arab-Hadrami ini. Menelisik proses islamisasi awal di Jawa, keberadaan situs makam Fatimah binti Maimun atau lebih dikenal dengan "Prasasti Leran" dan keberadaan makam Sunan Malik Ibrahim menunjukkan bahwa Gresik menjadi pintu gerbang masuknya Islam di Pesisir Utara jawa. Pertimbangan lain dari pemilihan Gresik sebagai lokus penelitian adalah keberadaan "Kampoeng Arab" di tengah kota yaitu di Kelurahan Gapurosukolilo dan Kelurahan Pulopancikan. Fakta ini menurut Yasmin (2010) menunjukkan eksistensi kewilayahan, sosial dan budaya dari Peranakan Arab di sana. ${ }^{4}$

\section{Nasionalisme Masyarakat Arab-Hadrami yang Dinamis}

Nasionalisme bisa disamakan dengan terma wataniyah dalam bahasa Arab. Menurut Jajang Jahroni (2000) konsep kebangsaan ini terlahir di kalangan orang-orang Arab-Hadrami karena desakan kondisi kala itu. Dinamika pergerakan nasionalisme Indonesia pra kemerdekaan menempatkan kelompok migran, termasuk Peranakan Cina dan Arab yang sudah lama tinggal di Hindia Belanda pada posisi yang terdesak. Pada saat itulah, kelompok migran yang merupakan minoritas terpaksa melakukan rekonsepsi tentang kebangsaan (wataniyah). Berbeda dengan Peranakan Cina yang sudah lebih dulu mengatasi dilema nasionalisme dengan memutuskan bahwa menjadi orang Cina bukan berarti tidak menerima gagasan nasionalisme Indonesia, orang-orang Arab-Hadrami justru masih terjebak pada dilema antara mempertahankan nasionalisme Hadramaut atau menerima gagasan nasionalisme Indonesia dan melupakan tanah air moyangnya tersebut. ${ }^{5}$

Pada awal abad 20-an, orang-orang Arab-Hadrami, terutama dari kalangan "totok" masih belum bisa menerima nasionalisme Indonesia

\footnotetext{
4 Yasmin Zaki Syahab, "Sistem Kekerabatan sebagai Katalisator Peran Ulama Keturunan Arab di Jakarta", Artikel dalam "Arab Society and Culture in Southeast Asia", Simposium Internasional Keempat Jurnal Antropologi Indonesia: "Indonesia in the Changing Global Context: Building Cooperation and Partnership?", Universitas Indonesia, Depok, 12-15 Juli 2005.

5 Jajang Jahroni, "Menjadi Pribumi di Negeri Orang: Pergumulan Identitas Masyarakat Arab di Indonesia", Book Review--Natalie Mobini-Kesheh, The Hadrami Awakening: Community and Identity in the Netherlands East Indie: 1990-1942 (Ithaca: Southeast asian Program Cornell University, 1999), Studia Islamika, Vol. 7, No. 3 (2000).
} 
dan melupakan Hadramaut sebagai asal kelahirannya. Bagi orangorang Arab-Hadrami, Hadramaut masih dipertahankan sebagai tanah air, sementara Indonesia hanya merupakan tempat perantauan (mahjar), di mana mereka mencari rejeki yang sewaktu-waktu dapat ditinggalkan ketika mereka memutuskan kembali ke tanah kelahirannya. Dilema ini menjadi hambatan bagi orang-orang ArabHadrami ketika harus mengambil keputusan untuk melibatkan diri dalam perjuangan merebut kemerdekaan kala itu. Negasi antara tetap menjadi Hadrami atau meleburkan diri dalam nasionalisme Indonesia menjadi kesulitan yang dihadapi oleh orang-orang Arab-Hadrami di Hindia Belanda pra-kemerdekaan Indonesia. Perdebatan tentang konsep wataniyah ini terjadi antara kelompok konservatif yang banyak diwakili dari golongan "Hadrami Totok" dan moderat yang diwakili oleh "Hadrami Peranakan".

Kondisi dilematis nasionalisme Arab-Hadrami berlangsung cukup lama, hingga A.R. Baswedan ${ }^{6}$ menginisiasi berdirinya Persatuan Arab Indonesia (PAI) pada 1934. Di antara visi perjuangan organisasi ini ialah mengokohkan nasionalisme bagi orang-orang Arab-Hadrami bahwa Indonesia harus diterima sebagai konsep wataniyab baik oleh kalangan Totok atau wulayti (yang terlahir dan masih terjaga genetiknya) maupun bagi Peranakan atau munvalad (yang terlahir di perantauan dan memiliki percampuran genetik dengan pribumi). Pada awalnya, inisiatif ini tentu tidak berjalan mulus karena mendapat penentangan dari kelompok konservatif, namun lambat laun gagasan A.R. Baswedan semakin direspons baik kelompok muda, baik dari golongan sayid dan bukan sayid. Posisi PAI dalam proses pengarusutamaan nasionalisme Indonesia bagi orang-orang ArabHadrami pada waktu itu sangat penting. Melalui organisasi inilah orang-orang Arab-Hadrami tergugah untuk menerima Indonesia sebagai visi kebangsaan, sehingga mereka termotivasi untuk melibatkan diri dalam proses perjuangan kemerdekaan dari penjajah sebagaimana yang sedang diupayakan oleh seluruh komponen bangsa terutama warga pribumi.

\footnotetext{
${ }^{6}$ Biografi sosok yang bernama lengkap Abdul Rahman Awad Baswedan ini telah disusun oleh Suratmin pada tahun 1989, kemudian diterbitakan ulang bersama Didi Kwartanada dalam versi baru, Biografi A.R. Baswedan: Membangun Bangsa Merajut Keindonesiaan (Jakarta: Penerbit Buku Kompas, 2014).

7 Suratmin dan Didi Kwartanada, Biografi A.R. Baswedan: Membangun Bangsa Merajut Keindonesiaan (Jakarta: Kompas, 2014), 111.
} 
Sebelum pendirian PAI, geliat untuk terlibat dalam proses pembangunan negara-bangsa (nation state) yang dicita-citakan, yakni Indonesia agar segera terlepas dari hegemoni kolonialisme serta mewujudkan masyarakat yang lebih maju sudah terlihat di kalangan orang-orang Arab-Hadrami. Salah satu bukti yaitu keterlibatan beberapa tokoh dari kalangan ini dalam organisasi-organisasi gerakan pada waktu itu seperti Serikat Islam. Keterlibatan orang-orang ArabHadrami di Serikat Islam awalnya sebagai penyokong dana dalam kegiatan-kegiatan organisasi. Meskipun pada akhirnya orang-orang Arab-Hadrami kehilangan posisi di dalam Serikat Islam karena dianggap bukan bagian dari masyarakat pribumi. Jajang Jahroni melihat kesadaran orang-orang Arab-Hadrami untuk terlibat dalam gerakan nasionalisme Indonesia itu terpantik oleh orang-orang keturunan Cina di Hindia Belanda yang lebih dulu melibatkan diri dalam proses pengembangan masyarakat dengan mendirikan organisasi Tiong Hoa Hwe Koan pada awal abad 20-an. Orang-orang keturunan Cina ini kemudian mendirikan sekolah-sekolah modern yang menjadi percontohan bagi lembaga pedidikan lain pada waktu itu. $^{8}$

Melihat perkembangan yang telah dicapai oleh orang-orang keturunan Cina di Hindia Belanda, lantas orang-orang Arab-Hadrami pada 1901 mendirikan organisasi pertama, yaitu Jamiat Kheir yang mendapat pengesahan dari Pemerintah Hindia Belanda pada 1905. Awalnya, Jamiat Kheir bergerak dalam bidang sosial dan pendidikan dengan mendirikan sekolah-sekolah modern. Namun, organisasi ini justru melahirkan dwi identitas bagi orang-orang keturunan ArabHadrami antara memosisikan diri sebagai Arab atau Muslim. Berdasarkan pada AD/ART, terlihat sekali Jamiat Kheir justru terjebak dwi identitas itu, karena keanggotaanya tidak dibatasi hanya untuk orang-orang Arab-Hadrami saja, tetapi organisasi ini juga terbuka bagi semua Muslim. ${ }^{9}$ Hal ini pun diterapkan di sekolahsekolah yang mereka dirikan, yang juga menerima siswa dari kalangan pribumi. Pada saat yang sama, tidak adanya penegasan bahwa Jamiat Kheir hanya diperuntukkan untuk orang Arab justru menciptakan ruang pembauran antara orang-orang Arab-Hadrami dengan pribumi.

\footnotetext{
8 Jahroni, "Menjadi Pribumi di Negeri Orang”, 172.

9 Miftahuddin, "Dinamika Komunitas Diaspora Hadrami dalam Gerakan al-Irsyad di Indoensia 1945-2007 (Disertasi-UIN Sunan Kalijaga Yogyakarta, 2017), 3.
} 
Beda dengan Jamiat Kheir, al-Irsyad (Jam'iyah al-Islah wa al-Irsyad alArabiyah) sebagai respons ketidakpuasan terhadap golongan sayid, tepat pada 1914 al-Irsyad didirikan oleh Ahmad Surkati. Sebelumnya, ulama dari Sudan ini sengaja didatangkan oleh tokoh Jamiat Kheir sebagai tenaga pengajar di sekolah milik Jamiat Kheir. Belakangan Surkati justru terlibat konflik dengan tokoh-tokoh golongan sayid karena pendapatnya tentang kafáab yang harus ditinggalkan dan kritiknya terhadap dominasi sayid di kalangan orang-orang ArabHadrami. Bagi Surkati, tidak ada perbedaan status sosial yang berbeda antara sayid dan non-sayid. Tidak menunggu waktu lama, al-Irsyad berkembang pesat dan mendapat simpati yang besar dari orang-orang Arab-Hadrami khususnya dari golongan non-sayid. Pada tanggal 11 Agustus 1915 al-Irsyad secara legal mendapat pengesahan dari Pemerintah Hindia Belanda. Apabila dibandingkan antara Jamiat Kheir dan al-Irsyad, justru al-Irsyad lah yang lebih melihatkan identitas kearaban atau lebih eksklusif. Selain dilema Arab yang digunakan sebagai nama organisasi, hal itu juga nampak pada tujuan resmi organisasi ini, yaitu menyelenggarakan kebiasaan adat istiadat menurut ajaran agama Islam, dan untuk menyebarkan di dalam kalangan orang-orang Arab tentang pengetahuan agama, bahasa Arab, dan bahasa Belanda. ${ }^{10}$

Pada masa selanjutnya, Jamiat Kheir dan al-Irsyad berada pada posisi yang berseberangan karena masing-masing mewakili dua kubu yang saling bertolak pandang yaitu golongan sayid dan golongan bukan sayid. Perdebatan antara Jamiat Kheir dan al-Irsyad terjadi seputar kafäab dan corak keagamaan, di mana Jamiat Kheir yang punya kecenderungan mempraktikkan tradisonalisme Islam dan alIrsyad yang mengadopsi semangat revivalisme Islam. Semangat puritarianisme yang didakwahkan oleh Surkati dan kelompoknya ini sering berbenturan dengan tradisi keislaman yang sudah lebih awal dipraktikkan secara luas di kalangan orang-orang Arab-Hadrami dari golongan sayid seperti praktik haul, maulid, tahlil, ziarah, dan terutama kebiasaan cium tangan kepada sesepuh mereka. Menurut Surkati, praktik keagamaan seperti itu jauh dari tuntunan al-Qur'ān dan sunnah, dan dapat menyebabkan pengultusan.

Kontestasi golongan sayid dan non-sayid di kalangan orang-orang Arab-Hadrami berlangsung cukup lama, bahkan bisa dikata berlanjut

10 Deliar Noer, The Modernist Muslim Movement in Indonesia, 1900-1942 (Singapore: Oxford University Press, 1973). 
hingga kini. Kiprah al-Irsyad yang mendapat simpati dari golongan non-sayid memicu golongan sayid mendirikan Rabithah Alawiyah pada 1927. Orientasi pendirian organisasi ini adalah menguatkan konsolidasi antarsayid di kalangan orang-orang Arab-Hadrami. Di dalamnya ada al-Maktab al-Däimi yang khusus mengurusi pencatatan nasab bagi orang-orang Arab-Hadrami dari golongan sayid. Keberadaan Rabithah Alawiyah tentu sangat berlawanan dengan alIrsyad yang menginginkan penghapusan status sayid di antara orangorang Arab-Hadrami. Setidaknya ketegangan antara dua organisasi Arab-Hadrami itu terlihat dari media cetak yang tersebar waktu itu. Mereka saling menyerang satu sama lain. ${ }^{11}$

Baru pada 1934, muncul sosok AR. Baswedan dari al-Irsyad yang mewakili Peranakan Arab yang berikhtiar menyatukan dua kelompok sayid dan non-sayid untuk bersama-sama terlibat dalam gerakan kemerdekaan dengan mendirikan organisasi Persatuan Arab Indonesia (PAI). Bagi AR. Baswedan sudah saatnya orang-orang Arab-Hadrami yang tinggal di Hindia Belanda menerima Indonesia sebagai Tanah Air. Padahal waktu itu generasi tua dari mereka lagi gencar-gencarnya memupuk patriotisme Hadramaut. Tak ayal upaya AR. Baswedan itu ditentang keras oleh golongan tua di internal al-Irsyad maupun Rabithah. Meskipun demikian dengan percaya diri, AR. Baswedan terus melakukan propaganda agar orang-orang Arab-Hadrami memilih menjadi bagian dari Indonesia dan bersama-sama memperjuangkan kemerdekaan dari penjajah. Menurut Patji (1990), PAI menjadi titik tolak integrasi orang-orang Arab-Hadrami dengan warga pribumi. ${ }^{12}$

Di bawah kepemimpinan A.R. Baswedan PAI telah menjadi lokomotif perubahan di kalangan orang-orang Arab-Hadrami tentang nasionalisme dan patriotisme. Orientasi mereka berubah dari Hadramantness menuju cita-cita Indonesia. Hal itu dibuktikan dengan gerakan-gerakan revolusioner seperti penyebaran gagasan nasionalisme Indonesia melalui pendidikan keluarga yang menjadi tugas kaum hawa dari Peranakan Arab. Selain itu ketika pendudukan Jepang, pemuda-pemuda PAI pun turut terjun ke medan perang melawan Jepang untuk mewujudkan kemerdekaan Indonesia. Dalam Suratmin dan Dwi Kwartanada (2014) dituliskan setidaknya ada dua

${ }^{11}$ Huub de Jonge, "Discord and Solidarity among the Arabs in the Netherlands East Indie, 1900-1942”, Indonesia, Vol. 55 (April 1993), 82.

12 Patji, "The Arabs of Surabaya," 91. 
nama Peranakan Arab yang terlibat dalam pertempuran waktu itu gugur, yaitu Bung Abu (Abubakar Alatas) di Semarang dan Alhadad yang gugur di Serpong bersama Lettu Soebianto Djojohadikusumo dan Taruna Soejono Djohadikusumo (keduanya adik Prof. Sumitro Soejono Djojohadikusumo). ${ }^{13}$ Keseriusan Peranakan Arab yang tergabung dalam PAI untuk mengakui nasionalisme Indonesia nampak dari keterlibatan mereka dalam organisasi pro kemerdekaan Indonesia seperti Gabungan Politik Indonesia (GAPI). Oleh anggota GAPI, Peranakan Arab sudah dianggap dan diterima sebagai sesama anak bangsa Indonesia. ${ }^{14}$ PAI waktu itu bergabung dan diterima menjadi anggota Majelis Islam A'la Indonesia (MIAI) atas dasar nasionalisme Indonesia yang mereka miliki dan perjuangkan. Karena nasionalisme Indonesia itu pulalah yang menyebabkan A.R. Baswedan tidak menghidupkan kembali PAI pasca-kemerdekaan dengan alasan bahwa tidak ada lagi golongan Arab, yang ada adalah warga negara Indonesia.

Ismail Fajrie Alatas (2011) berpandangan bahwa tantangan nasionalisme bagi orang-orang Arab-Hadrami tidak selesai setelah tercapainya kemerdekaan Indonesia. Meskipun mereka dapat diterima sebagai bagian warga negara Indonesia pasca kemerdekaan dan telah membuktikan diri terlibat dalam sejarah perjuangan dan mengisi kemerdekaan. Namun, sebagian kelompok masih tetap memandang bahwa mereka adalah kelompok migran dan minoritas. Tantangan nasionalisme pasca kemerdekaan lebih berat ketika untuk membaur secara total di lingkungan sosial sebagai bagian warga negara, Peranakan Arab ini dihadapkan pada pergumulan identitas antara mewarisi dan melestarikan tradisi leluhur dengan tuntutan untuk membuktikan loyalitas terhadap konsep nasionalisme Indonesia. Sementara ketika harus menjadi Indonesia seutuhnya, maka yang mungkin terjadi tradisi asal itu digantikan dengan tradisi lokal yang berlaku umum, seperti budaya berpakaian, adat istiadat keseharian, berbahasa dan sebagainya. Ketika itu terjadi, maka Peranakan ArabHadrami ini akan kehilangan sama sekali identitas asal leluhur mereka. ${ }^{15}$

\footnotetext{
${ }^{13}$ Suratmin dan Didi Kwartanada, Biografi A.R. Baswedan, 107.

14 Ibid., 112.

${ }^{15}$ Ismail Fajrie Alatas, "Becoming Indonesians: The Bā 'Alawī in the Interstices of the Nation”, Die Welt des Islams, Vol. 51 (2011), 45-74.
} 
Tantangan nasionalisme bagi warga keturunan baik Arab dan Cina di Indonesia semakin berat pasca-kemerdekaan. Lebih-lebih ketika isu nasionalisme menjadi hal yang sensitif di tengah masyarakat pascareformasi. Misalnya ketika isu-isu itu digulirkan di arena politik seperti pada pemilihan Presiden tahun 2014 lalu, ketika Joko Widodo diserang sebagai keturunan Cina, atau ketika pemilihan Gubernur DKI Jakarta tahun 2016, di mana kedua calonnya, Basuki Thahaja Purnama yang Peranakan Cina dengan Anies Baswedan yang Peranakan Arab, isu nasionalisme di kalangan peranakan juga ramai diperbincangkan, atau bahkan ada sebagian yang menyangsikan patriotisme mereka dari warga keturunan yang tampil untuk mengisi jabatan publik. Sensivitas etnik semakin terasa mengangah dewasa ini seiring gelombang politik populisme yang menggejalah secara global, di mana isu-isu etnik sering kali dimunculkan sebagai upaya untuk memenangkan kontestasi politik. Selain itu, kenyataan bahwa koloni Arab ataupun Cina masih tidak memiliki kesempatan yang luas untuk mendapatkan hak sebagaimana warga pribumi.

Potret lain dari orang-orang keturunan Arab-Hadrami di Indonesia yang menarik akhir-akhir ini adalah merebaknya fenomena habibisme, yaitu gelombang sosial yang ditandai dengan kelahiran kelompok-kelompok yang mengidolakan tokoh dari kalangan habib, atau individu yang merupakan Peranakan Arab dari golongan sayid. Pasca-reformasi tahun 1998, majelis-majelis taklim di bawah asuhan seorang habib seperti Majelis Rasulullah dengan tokoh sentralnya Habib Munzir Musawa dan Nurul Mustafa yang dipimpin oleh Habib Hasan Assegaf mewarnai gairah keagamaan generasi muda di Ibukota Jakarta. Kemudian di tahun 2004 muncul pula Habib Syech Assegaf dengan gerakan majelis selawat Ahbabul Mustafa. Habib Syech sangat populer di kalangan generasi muda masa kini, majelis selawat yang diasuhnya tidak pernah sepi dari para pengagumnya yang menamakan diri mereka dengan Syecher Mania. Upaya tokoh-tokoh Peranakan Arab seperti Habib Munzir dan Habib Syech serta tokoh-tokoh muda Peranakan Arab lainnya dalam meraup simpati masyarakat merupakan keberhasilan dari proses adaptasi untuk mengokohkan identitas mereka di tengah nasionalisme Indonesia.

Selain beberapa fenomena habibisme di atas, ada yang paling fenomenal. Kemunculan Habib Rizieq Syihab dengan organisasi Front Pembela Islam (FPI) telah menjadi fakta lain dari pergumulan Peranakan Arab di tengah nasionalisme Indonesia. Rizieq dan FPI 
yang mengusung gerakan amr ma'rüf nahy munkar, semenjak awal pendirian selalu mengundang kontroversi melalui dakwah-dakwah yang mereka perjuangkan. Beberapa kali selama kurun waktu dari awal pendirian organisasi ini hingga waktu Pemilihan Gubernur DKI Jakarta tahun 2016 lalu, Rizieq dan FPI sering menjadi topik perbincangan publik. Terlepas dari kontroversi yang mereka ciptakan, model dakwah yang ditawarkan Rizieq dapat diakui efektif karena mampu menarik perhatian kelompok muda dalam jumlah yang kemudian bergabung ke dalam organisi ini. Menurut Fachri Ali (2016) yang menyebut fenomena mengorbitnya Rizieq di kancah nasional menunjukkan fenomena perubahan struktural pasca-Orde Baru. Kondisi ini disebabkan proses alienasi sosial, ekonomi, dan politik yang mendera masyarakat dewasa ini. Publik terindikasi kehilangan patron populis yang diidam-idamkan karena merasa jengah dengan sistem tenknokratik oraganisasi kemasyarakatan yang dikenal selama ini. $^{16}$

Kemunculan fanatisme ketokohon terhadap Rezieq sejauh ini tidak terjadi hanya pada generasi muda sesama Peranakan Arab, justru mayoritas simpati itu datang dari kalangan bukan dari Peranakan Arab yang berusia muda atau bisa digolongkan milenial. Di Gresik sendiri, popularitas Rizieq dan FPI sampai artikel ini ditulis juga mengalami peningkatan pasca-Aksi 212 yang digelar di Monas Jakarta. Setidaknya popularitas itu dapat dibuktikan dengan keberadaan FPI Cabang Gresik dan pada kegiatan Haul Habib Abu Bakar Assegaf yang dilaksanakan di Bulan Zulhijah tahun 2018, atribu-atribut yang biasanya identik dengan FPI pun turut mewarnai acara tersebut. Fenomena Rizieq ini turut menggambarkan bahwa Peranakan Arab pun memiliki peran dalam proses demokrasi yang berlangsung di Indonesia terlepas kontroversi yang timbul darinya. Jika kembali melihat sejarah, keterlibatan Peranakan Arab dalam sejarah politik di Indonesia dengan apa yang tengah terjadi saat ini seolah menegaskan ada pencarian identitas di kalangan sebagian Peranakan Arab yang belum tuntas tentang nasionalisme Indonesia. Hal ini sekaligus memberi gambaran bahwa komunitas ini sangat dinamis dalam menyikapi perkembangan perpolitikan di Indonesia.

\section{Visi Keindonesiaan bagi Peranakan Arab di Gresik}

Peran orang-orang Arab-Hadrami di Indonesia salah satunya

${ }^{16}$ http://indopress.id (22 Juni 2018) 
dapat dilihat dari Sumpah Pemuda Peranakan Arab yang dikumandangkan pada 1934 di Semarang, berisikan: (1) Tanah Air Peranakan Arab adalah Indonesia; (2) Karenanya harus meninggalkan kehidupan sendiri (isolasi). ${ }^{17}$ Artinya, gerakan ini dimaksudkan agar komunitas Peranakan Arab tidak menyendiri dan mulai berbaur secara masif dengan masyarakat pribumi. Namun, isu nasionalisme yang dewasa ini meruncing menempatkan orang-orang keturunan ArabHadrami pada posisi yang tidak nyaman. Kemunculan beberapa tokoh Peranakan Arab yang terlibat isu radikalisme dan ideologi transnasional meningkatkan kecurigaan terhadap orang-orang dari keturunan Arab-Hadrami yang berada di Indonesia karena dianggap kurang atau bahkan tidak memiliki komitmen nasionalisme Indonesia. Padahal, tokoh-tokoh Peranakan Arab itu hanya mewakili dari sebagian kecil eksistensi mereka di republik ini.

Selain beberapa tokoh Peranakan Arab yang terindikasi atau terlibat dalam beberapa aktivitas radikalisme dan ideologi transnasional, banyak di antara Peranakan Arab yang justru terlibat aktif dalam upaya membangun kehidupan bangsa yang lebih baik. Berbagai profesi yang digeluti menunjukkan kontribusi mereka sebagai bagian dari warga negara Indonesia. Tokoh seperti Ali Alatas (Menteri Luar Negeri), Fuad Bawazir (Menteri Keuangan), dan Fuad Hasan (Menteri Pendidikan), mereka ini pernah menduduki jabatan starategis di era Presiden Suharto. Tidak berhenti di zaman Orde Baru, di era Presiden Abdurrahman Wahid pun ada tokoh dari keturunan Arab-Hadrami yang menempati posisi menteri seperti Alwi Shihab (Menteri Luar Negeri). Tradisi ini dilanjutkan di era Presiden Megawati ada Said Agil Munawar (Menteri Agama), di era Susilo Bambang Yudhoyono ada Salim Segaf al-Jufri (Menteri Sosial), sedangkan di era Presiden Joko Widodo Anies Baswedan sempat menjabat sebagai Menteri Pendidikan.

Sederet nama-nama yang disebutkan di atas hanya sebagian profil keturunan Arab-Hadrami yang terbukti ikut berkiprah dalam pemerintahan dari era Orde Baru hingga Reformasi. Masih banyak lagi Pernakan Arab yang juga memiliki kiprah di bidang-bidang lain

17 Lihat selengkapnya dalam Hamid Algadri, Islam dan Keturunan Arab (Bandung: Mizan, 1996). Lihat juga Husain Haikal, "Indonesia-Arab dalam Pergerakan Kemerdekaan Indonesia 1900-1942” (Tesis--Universitas Indonesia Jakarta, 1987). Lihat juga Huub de Jonge, "Abdul Rahman Baswedan and the Emancipation of the Hadramis in Indonesia”, Asian Journal of Social Science, Vol. 32, No. 3 (2004), 373400. 
seperti M. Quraish Shihab (Guru Besar UIN Syarif Hidayatullah Jakarta), Habib Luthfi bin Yahya (Ketua Jamiyah Ahlit Tariqah alMuktabarah), Munir bin Said (Aktivis Hak Asasi Manusia), dan Munzir al-Musawa (Dai dan Pimpinan Majelis Rasulullah). Kiprah Peranakan Arab-Hadrami tidak hanya terpusat pada satu bidang, melainkan hampir seluruh profesi terdapat Peranakan Arab yang berada di sana seperti menjadi akademisi, pekerja seni, wartawan, penulis hingga atlet. Hal ini tentu mengokohkan keterlibatan mereka dalam proses berbangsa dan bernegara untuk konteks Indonesia.

Tidak hanya secara individual, peranan Peranakan Arab juga dijumpai secara kolektif seperti keterlibatan mereka dalam pendirian lembaga-lembaga pendidikan dan sosial. Di Gresik yang menjadi lokus riset ini, peran Peranakan Arab dalam menegaskan visi keindonesiaan dapat ditemukan melalui keterlibatan mereka pada bidang pendidikan dan sosial keagamaan. Di kampung Arab yaitu Desa Gapurosukolilo dan Desa Pulopancikan di mana komunitas Peranakan Arab tinggal dijumpai beberapa lembaga pendidikan yang dalam praktiknya tidak hanya diperuntukkan bagi Peranakan Arab saja melainkan juga menerima siswa dari luar komunitas ini bahkan mengutamakan dari keluarga yang kurang mampu. Dalam bidang sosial keagamaan, beberapa majelis taklim untuk masyarakat umum juga diasuh oleh tokoh-tokoh agama dari Peranakan Arab. Ada beberapa lembaga pendidikan Islam yang didirikan oleh Peranakan Arab di Gresik yaitu YIMI Full Day School, ${ }^{18}$ Sekolah Fatimiyah, Madrasah Diniyah Ihya Ulumuddin, dan Muhajirin Center.

Untuk memotret bagaimana visi keindonesian di kalangan milenial Peranakan Arab di Gresik, peneliti melakukannya dengan mendalami kegiatan di lembaga pendidikan yang menjadi basis penanaman nasionalisme Indonesia. Pertama, Yayasan Islam Malik Ibrahim (YIMI). Awalnya, YIMI ini bernama "Jajasan Madrasah al-Arabijah alIslamijah" yang didirikan pada tahun 1950. Ketua pengurusnya waktu itu adalah Zain Abdullah al-Kaff. Motivasi pendirian yayasan ini didasari oleh keinginan untuk ikut serta mencerdaskan kehidupan bangsa. Berdasarkan cerita dari Fatimah Shahab, dulu kakeknya mengungkapkan bahwa pendiri YIMI dulu adalah kakek buyutnya.

18 SMP Yayasan Islam Malik Ibrahim (YIMI) didirikan di Gresik dengan nama SMP Islam Malik Ibrahim pada tahun 1959 dengan SK Nomor: 158/U.2213/104.2/13.81 pada tanggal 29 Desember 1981 dan diperbarui dengan SK Kepala Kantor Wilayah Departemen Pendidikan dan Kebudayaaan Provinsi Jawa Timur Nomor: 00173/104.7.4/1990 pada tanggal 15 Januari 1990. 
"Kakek Buyut saya yang mendirikan YIMI. Pengurus yayasan yang sekarang ini juga masih keluarga saya". ${ }^{19}$ Alasan pendirian YIMI menurut keterangan Fatimah berdasarkan cerita kakeknya termotivasi oleh ketiadaan akses pendidikan bagi anak-anak di tempat tersebut. Sekarang ini YIMI sudah menyelenggarakan pendidikan dari jenjang Play Group hingga Sekolah Menengah Pertama. Namun, ketika penelitian ini dilakukan mayoritas siswa YIMI bukan dari kalangan Peranakan Arab, melainkan kebanyakan dari warga pribumi.

Kedua, Yayasan Pendidikan Islam Fatimiyah yang sudah ada sejak tahun 1949. Berdasarkan keterangan dari Umamah selaku kepala sekolah, "Sekolah Fatimiyah awalnya berbentuk madrasah diniyah. Kemudian berkembang dan didaftarkan menjadi sekolah formal mengikuti pemerintah". ${ }^{20}$ Sebagai penegasan bahwa Peranakan Arab merupakan warga negara Indonesia, Umamah mengatakan bahwa di sekolah para murid diajarkan pendidikan Kewarga negaraan. Menurutnya pula, bela negara juga merupakan keharusan. "Di sekolah kami juga ada pelajaran PPKN, Pramuka, ya, semuanya ada. Kalau masalah bela negara, harus. DI sekolah Fatimiyah, kita menerapkan semuanya; upacara bendera, hafalan Pancasila, dan pengenalan UUD 1945. Kita juga mengadakan lomba 17 Agustus dan kegiatan-kegiatan peringatan hari nasional lainnya". Mengenai penanaman nasionalisme Indonesia di kalangan keluarga Peranakan Arab, Umamah mengatakan bahwa Pancasila dan UUD 1945 selalu ditanamkan bagi siswa-siswi di sekolah tidak terkecuali kepada anak-anak dari keluarga Peranakan Arab. Keluarga Arab sudah menganggap diri mereka adalah warga negara Indonesia sehingga hal-hal yang berkaitan dengan nasionalisme diterapkan sebagaimana warga negara dari bukan keturunan. Tapi, bagaimanapun Peranakan Arab masih menyimpan ingatan tentang Hadramaut sebagai tanah leluhurnya, seperti yang diungkapkan Umamah, "Saya rindu tanah asal leluhur saya. Saya ingin ke makam awliy a' di sana. Cara mengobati kerinduan itu kami masih mempertahankan kuliner khas Hadramaut sebagai menu keluarga atau ketika ada acara-acara, kami juga menerapkan tradisi-tradisi seperti di Hadramaut". ${ }^{21}$

Selain kedua lembaga pendidikan formal yang telah disebutkan yaitu YIMI dan Fatimiyyah, di kampung Arab Gresik terdapat

${ }^{19}$ Fatimah, Wawancara, Gresik 27 Juni 2018.

${ }^{20}$ Umamah (Kepala SD Fatimiyah), Wawancara, Gresik 5 Mei 2018.

${ }^{21}$ Ibid. 
lembaga pendidikan non-formal seperti Madrasah Ihya Ulumuddin dan madrasah yang dikelola oleh Muhajirin Center. Dua lembaga pendidikan non-formal tersebut menyelenggarakan pendidikan alQur'ān dan diniyah. Habib Ahmad b. Abu Bakar b. Ali b. Abu Bakar Assegaf pengelola Madrasah Ihya Ulumuddin menyebutkan bahwa tujuan dari pendirian madrasah adalah untuk ikut berkontribusi dalam mencerdaskan anak bangsa, khususnya pada aspek kegamaan dan akhlak. Habib Ahmad menceritakan, setelah dirinya menamatkan pendidikan di Darul Mustafa Yaman yang diasuh oleh Habib 'Umar b. Hāfiz, ia menemui gurunya Habib Baharun, pengasuh Pondok Pesantren Darul Lughah Wa Dakwah Bangil. Oleh gurunya ia disarankan untuk membuka lembaga pendidikan diniyah di Gresik. Habib Ahmad menyebut bahwa motivasinya untuk mendirikan madrasah karena merasa resah dengan perkembangan terkini pemahaman agama dan akhlak di antara generasi muda, terutama dari keluarga Peranakan Arab. Selain itu, sebagai keturunan dari keluarga sayid, Habib Ahmad merasa terpanggil meneladani cara hidup leluhurnya yang dikenal memiliki konsistensi dalam berdakwah dan mendidik masyarakat. Berkaitan dengan apa yang divisikan tentang nasionalisme Indonesia habib yang masih keturunan tokoh terkemuka di kalangan Peranakan Arab yaitu Habib Abu Bakar Asegaf ${ }^{22}$ menyebutkan, "Peran kami bagi Indonesia adalah mendidik akhlak masyarakat dan mengajarkan Islam". Menurutnya, tanpa akhlak yang baik dan pengetahuan agama yang benar, bangsa Indonesia akan sulit menjadi bangsa yang beradab sebagaimana yang diamanatkan Pancasila dan UUD $1945 .^{23}$

Mengenai penegakan syariat dalam negara, Habib Ahmad mengatakan bahwa hal itu harus diwujudkan karena di dalam referensi kitab-kitab fiqh, para ulama mengatakan demikian. "Kami setuju penegakan hukum-hukum Islam. Mewujudkan syariat Islam hukumnya wajib. Di dalam kitab-kitab fiqh begitu adanya". Namun pola penegakkannya berbeda dengan apa yang selama ini dikampanyekan oleh Hizbut Tahrir Indonesia (HTI). Jika HTI ngotot dengan penerapan khiläfah, Habib Ahmad tidak demikian. Menurutnya, masyarakatnya dulu yang harus disyariatkan. Artinya, masyarakat harus diberikan pemahaman mengenai syariat Islam agar kemudian diamalkan. Penegakan syariat itu tidak dengan cara

22 Ahmad, Wawancara, Gresik 7 Juni 2018.

${ }^{23}$ Ibid. 
mendirikan khiläfah. Habib Ahmad menuturkan, "Untuk membangun Indonesia yang bersyariat adalah dengan cara mengarahkan masyarakatnya agar bersyariat. Kalaupun pemerintah menerapkan syariat tapi masyarakat masih belum bersyariat dengan benar, yang ada malah setengah-setengah atau hanya karena terpaksa saja menjalankan syariat. Ini tidak benar". ${ }^{24}$ Selain itu, Habib Ahmad berpikiran bahwa tradisi-tradisi yang sudah lama dikenal masyarakat kalau itu tidak bertentangan dengan syariat pastilah tidak ada masalah. Namun apabila ada yang tidak sesuai dengan syariat, maka harus diarahkan agar sesuai, bukan malah dihilangkan. Pandangan Habib Ahmad ini mencerminkan bahwa ia menyadari akan keragaman yang ada di Indonesia.

Habib Ahmad meyakini bahwa di dunia ini belum ada negara yang menerapkan syariat secara utuh meskipun di Arab Saudi. "Tapi saat ini saya kira belum ada negara yang bersyariat secara untuh. Bahkan di Arab sana tidak menjalankan secara utuh. Masih setengah-setengah". ${ }^{25}$ Sementara mengenai Pancasila, Habib Ahmad setuju dengan Pancasila karena tidak melanggar syariat. "Pancasila kami setuju. Karena tidak melanggar syariat. Menegakkan syariat Islam tidak harus dengan mengubah Pancasila." 26 Dengan demikian melihat dari penjelasan yang disampaikan, Habib Ahmad mengesankan sosok Peranakan Arab yang telah menyerap nasionalisme Indonesia dengan kesadarannya pada asas ideologi negara yaitu Pancasila dan penerimaannya terhadap keragaman masyarakat. Namun, pada saat yang sama sebagai Muslim, ia menyimpan keinginan agar syariat Islam diterapkan meskipun membatasi bahwa hal itu cukup dilakukan dengan mendidik masyarakat dan megarahkannya untuk menjalankan syariat secara benar. Sebagaiman yang ia tuturkan, "Kalau sekarang masyarakat masih belum siap. Jadi kita jalani dulu hukum yang berlaku di Indonesia. Tidak perlu memaksakan kehendak untuk menerapkan syariat Islam. Masyarakatnya dulu diperbaiki. Kalau masyarakat sudah siap, barulah syariat Islam diformalkan melalui undang-undang. Itulah gunanya kita memperbanyak pengajian". ${ }^{27}$

\footnotetext{
${ }^{24}$ Ibid.

25 Ibid.

${ }^{26} \mathrm{Ibid}$

${ }^{27}$ Ibid.
} 


\section{Antara Merawat Tradisi dan Menggelorakan Nasionalisme}

Masalah yang terus membelit Peranakan Arab di tempat barunya adalah persoalan dwi identitas yang melekat pada diri mereka. Pada saat yang sama, setiap Peranakan Arab dihadapkan pada dilema antara tanggung jawab mewarisi tradisi leluhur dan melebur dalam lingkungan sosial di mana mereka berada. Di kampung Arab Gresik dilema itu juga dirasakan oleh umumnya warga Peranakan Arab. Menurut Fajrie (2011) yang menyebutkan bahwa kemampuan bertahan orang-orang Arab-Hadrami agar identitas Hadraminya tidak hilang salah satunya melalui peran tarekat Alawiyah. ${ }^{28}$ Merawat tradisi leluhur menjadi salah satu hal penting bagi golongan sayid terutama dalam hal praktik keagamaan. Seperti yang dituturkan Ahmad, "Kami berusaha untuk mengajarkan Islam agar menjadi muslim yang hakiki sebagaimana dulu Wali Sanga. Dengan gaya yang macam-macam yang intinya mengajarkan Islam seperti tarekat Ba' Alawi (atau Alawiyah). Dalam tradisi $\mathrm{Ba}$ ' Alawi yang sumbernya dari Imam al-Haddad, pendidikan dimulai dari membersihkan penyakit hati dengan mujahadah. Kedua dengan terus belajar. Ketiga adab atau akhlak yang baik dan terakhir dengan memperbanyak wirid." ${ }^{29}$

Bagi Ahmad yang tergolong sayid dan mempunya garis keturunan dari marga besar, Asegaf juga termasuk cucu dari tokoh agama terkenal di kalangan Peranakan Arab, Habib Abu Bakar Asegaf, bahwa mengikuti salaf (leluhur) dari kalangan sayid itu merupakan kewajiban bagi generasi setelahnya. Tidak hanya akidah, tapi juga kebiasaan-kebiasaan, adab (perilaku) hingga hal-hal terkecil seperti labjah logat. Misalnya huruf qäf. Dalam tradisi para sayid di Hadramaut itu dibaca gaf. Maka, di Gresik pun dan umumnya di Indonesia juga masih dipertahankan. Namun, Ahmad secara pribadi masih menjaga salah paham yang bisa disebabkan oleh itu ketika menjadi imam salat dengan jemaah bukan dari Peranakan Arab. Karena dikhawatirkan akan menimbulkan salah paham. "Kalau mengimami salat di luar kalangan habaib (Peranakan Arab-pen), saya membaca qäf agar tidak membingungkan masyarakat". ${ }^{30}$

Mengenai tradisi yang terus dijaga, Umamah mengatakan bahwa Orang tua masih sangat menjaga tradisi ke-Arabannya. "Orang tua masih sangat menjaga tradisi ke-Araban. Mulai dari tradisi cara makan,

\footnotetext{
${ }^{28}$ Alatas, "Becoming Indonesians", 45-74.

${ }^{29}$ Ahmad, Wawancara, Gresik 7 Juni 2018.

${ }^{30}$ Ibid.
} 
masuk rumah, dan menjalankan ibadah. Itu semua erat kaitannya dengan mazhab atau tata cara dari sana (Hadramaut-pen). Sampai sekarang masih berjalan. Mungkin dalam sepuluh tahun terakhir, warga muda Arab sudah banyak yang berkurang". ${ }^{31}$ Umamah juga mengaku ingin terus menjaga tradisi tersebut. Caranya dengan menjaga pendidikan putra-putranya. "Kalau saya sendiri, masih ingin tetap menjaganya. Saya masukkan anak saya ke pondok yang memang masih menjaga tradisi itu di Pondok Pasuruan (Pondok Pesantren yang diasuh Habib Taufiq Assegaf-pen). Di sana sekolah formal dan karakteristik Pendidikan Hadramaut masih diikuti bahkan dimasukkan dalam kurikulum". 32

Apa yang dirasakan dan dipraktikkan di kalangan Peranakan Arab sebagaimana yang diungkapkan oleh Ahmad dan Umamah tentang persoalan dualisme identitas antara mewarisi tradisi Hadrami dengan mengungkapkan sisi nasionalisme Indonesia pun sebenarnya dialami oleh generasi muda Peranakan Arab seperti Zein bin Smith (15). Zein adalah seorang pemuda Peranakan Arab yang setiap harinya membantu Abinya (panggilan Ayah) berjualan Pertalite eceran di depan gang rumahnya. Masih terlihat dari raut wajahnya identitas keArab-an; berambut ikal, hidung mancung dan berperawakan besar. Ia anak kedua dari lima bersaudara dari keluarga bermarga Bin Smith yang masih mempertahankan kafä'ah. Ayahnya bernama Alwi bin Smith (50) wiraswasta berasal dari Pekalongan yang menikah dengan perempuan keturunan dari marga Alaydrus yang berasal dari Pulopancikan Gresik. Kini anak-anak dari perkawinan itu mengikuti marga Bin Smith (salah satu klan sayid). Keluarga Zein masih memegang teguh perihal kafä'ah. Dulu Ayahnya, Alwi menikah dengan istrinya juga karena pertimbangan bahwa calonnya adalah seorang syarifah. Semenjak tingkat Taman Kanak-kanak (TK), Zein sudah bersekolah di sekolah yang mayoritas siswanya bukan warga Peranakan Arab sepertinya. Di salah satu TK Swasta Zein sudah membangun lingkungan sosialnya yang tidak lagi eksklusif karena di lingkungan belajarnya, Zein berteman dengan anak-anak seusianya dari etnis Jawa dan Madura.

Di jenjang pendidikan berikutnya, Zein melanjutkan pendidikan di Madrasah Ibtidaiyah (MI) al-Fathimiyah. Sekolah ini tidak jauh dari tempat tinggalnya. Madrasah ini awal kali didirikan oleh Ustaz al-

${ }^{31}$ Umamah (Kepala SD Fatimiyah), Wawancara, Gresik 5 Mei 2018.

32 Ibid. 
Habib Husin bin Muhdhor bin Shahab pada tahun 1338/1939 M. Madrasah ini sejak awal tidak membedakan latar etnis siswanya, meskipun dulu mayoritas anak-anak yang bersekolah di situ merupakan Peranakan Arab. Pendirian madrasah ini didorong oleh tanggung jawab sosial dari Husin bin Sahab ketika di sekitar kampung Arab belum ada lembaga pendidikan Agama. Waktu itu madrasah ini mendapat pengakuan dari pemerintah Hindia Belanda sebagai lembaga penyelenggara pendidikan keagamaan yang sah. Segala kebutuhan pendanaan di awal pendirian masih ditanggung oleh kelurga Bin Shahab sekaligus sebagai tenaga pendidik di sana. Sebelum berubah nama menjadi MI Fathimiyah pada tahun 1950, madrasah ini bernama Raudlatul Athfal. Sejak dulu madrasah ini selalu menanamkan cinta tanah air kepada siswa-siswanya melalui kegiatan Hizbul Wathon (sekarang: Pramuka).

Seperti teman-temannya yang lain dari Peranakan Arab, Zein Bin Shahab sudah dibiasakan dengan lingkungan pendidikan multikultur. Meskipun kampungnya sendiri tetangga kanan-kirinya tidak lain adalah Peranakan Arab. Kini Zein duduk di bangku Sekolah Menengah Pertama. SMP Nurul Islam di Desa Pongangan menjadi pilihan Zein bersekolah. Sekali lagi Zein membiasakan diri bersosial dengan anak-anak dari etnis Jawa. Di keluarganya pengetahuan agama (Islam) dan akhlak menjadi prioritas. Ayahnya di masa muda pernah belajar di pesantren yang diasuh oleh Habib Husein al-Habsyi atau yang lebih dikenal dengan YAPI (Yayasan Pendidikan Islam) Bangil. Dulu pesantren ini menjadi tempat rujukan bagi keluarga Peranakan Arab dalam memperdalam Islam. Pesantren itu mewajibkan para santrinya berbicara Bahasa Arab dan mentradisikan berpakaian selayaknya orang Arab, yakni berjubah. Melalui pendidikan di keluarganya itu Zein dibiasakan dengan tradisi keluarga Hadrami yang sudah dipraktikkan lama oleh ayahnya. Meskipun dibiasakan dengan tradisi Arab, penampilan Zein sehari-hari tidak berbeda dengan anakanak seusianya dari etnis Jawa dan Madura; bercelana, berkaos dan berbahasa Indonesia, sering juga berbahasa Jawa. Bahkan Zein tidak mengusai kemampuan bahasa Arab dengan baik.

Seperti Zein (15), Fatimah (19) mengungkapkan sebagai Peranakan Arab dari golongan sayid, ia tidak merasa terasing atau terisolasi dari masyarakatnya. Pendidikan telah melebur sekat etnik itu ketika Fatimah memilih untuk bersekolah di sekolah-sekolah negeri, di mana di sana siswa-siwanya dari berbagai etnik; Jawa, Madura, Cina, 
dan Arab. Hingga kuliah pun ia memilih meneruskan di salah satu universitas swasta di Gresik sebab pertimbangan jarak dan budaya yang heterogen di sana. Sebagai Peranakan Arab, yang kebetulan keluarganya dikenal sebagai tokoh "Bin Shahab" karena punya andil melopori pendirian Yayasan Islam Malik Ibrahim hingga sekarang besar dan memiliki lembaga pendidikan mulai TK hingga SMP, serta termasuk sekolah "favorit" di Gresik kota. Fatimah menilai apa yang dilakukan kakeknya ketika mendirikan sekolah untuk anak-anak di Gapurosukolilo itu sebagai wujud nasionalisme keindonesiaan. Fatimah menegaskan, "Sebagai cucunya, saya pun harus bisa meneladani itu". ${ }^{33}$ Pada saat yang sama ketika Fatimah mempunyai cita-cita melakukan hal yang bermanfaat bagi masyarakat di sekitarnya seperti yang pernah dilakukan oleh pendahulunya sebagai buki nasionalisme Indonesia, karena kelurganya dikenal sejak dulu secara turun temurun mewarisi resep-resep kuliner khas Timur Tengah seperti nasi Kebuli, kue Ka'ka', dan banyak hidangan khas Hadramaut lain, ia merasa punya kewajiban mewarisi itu.

Berdasarkan pengalaman dari Ahmad, Umamah, Zein dan Fatimah yang sudah dipaparkan di atas, dapat diketahui bahwa Peranakan Arab sekarang pun masih berhadapan dengan dwi identitas yang harus mereka sejajarkan secara porposional. Sebagai warga negara Indonesia, mereka tetap menunjukkan sikap kompromitif untuk menerima keragaman di lingkungan sosial mereka yang memang heterogen. Hal ini tercermin dari pergaulan mereka baik di masyarakat maupun di lingkungan pendidikan. Rasa nasionalisme Indonesia mereka terbangun dari proses pendidikan formal yang mereka lalui sekaligus interaksi dengan sesama warga negara Indonesia dari etnis lain seperti Jawa dan Madura. Bagi Peranakan Arab bahwa komitmen mereka terhadap Indonesia itu diukur melalui peran mereka di masyarakat di bidang agama, sosial, ekonomi, dan pendidikan. Pada saat yang sama Peranakan Arab pun masih mewarisi tradisi dari leluhur mereka terutama berkaitan dengan praktik keagamaan, budaya, dan kuliner yang diajarkan secara turun-temurun dalam keluarga. Aspek penting dari upaya mempertahankan identitas Hadrami itu dapat ditemukan dari konsistensi Peranakan Arab memegang prinsip kafä ah dalam pernikahan. Hal ini dimaksudkan agar identitas asal Hadramisme tidak hilang terutama yang berhubungan dengan genetik. Untuk menjaga nasab ini, Peranakan

${ }^{33}$ Fatimah, Wawancara, Gresik 4 Juni 2018. 
Arab utamanya dari golongan sayid masih memberlakukan kafäab sebagai sistem kontrol genetik.

\section{Kontinuitas dan Diskontinuitas Hadramisme}

Pergulatan identitas orang Arab-Hadrami sebagai akibat dari diaspora, dapat dirujuk pada fenomena diaspora "tua", yang telah berlangsung dalam skala besar sejak pertengahan abad ke-18 hingga akhir 1950-an. ${ }^{34}$ di tengah diskriminasi yang diberlakukan oleh Kolonial Belanda, orang Arab-Hadrami memainkan peranan baik di bidang sosial, politik, maupun ekonomi. Para imigran Hadrami ini turut ambil bagian dalam memperluas pasar bisnis, memperoleh kesejahteraan, dan mengirimkannya kembali ke tanah Hadramaut. ${ }^{35}$ Kontak antara Jawa dan Hadramaut ini sekaligus menjadi gambaran eksistensi komunitas Hadrami di kawasan Asia Tenggara. Para pelaku diaspora Hadrami, tidak hanya mengirimkan uang kepada keluarga, tetapi juga mengirim anak-anak ke Hadramaut untuk memperoleh pendidikan. Bahkan, ada sebagian dari yang menjalin kontak dengan aktivitas-aktivitas politik di Hadramaut. ${ }^{36}$ Namun, oleh karena gagasan nasionalisme dan diskursus mengenai nation-states, aktivitas ini menurun drastis. ${ }^{37}$

Di era sekarang, Peranakan Arab secara umum memang mengalami dilema identitas antara mewarisi tradisi leluhurnya atau meleburkan diri sebagai warga negara Indonesia sepenuhnya. Pada proses ini, memang ada beberapa hal yang terus dipegang dan yang ditinggalkan. Misalnya mengenai pernikahan. Golongan syarifah tidak diperkenankan untuk menikah dengan golongan bukan sayid. Ini merupakan salah satu cara komunitas ini menjaga identitas etniknya. Namun, pada beberapa kasus kafä ah ini kurang dipegangi oleh Peranakan Arab bukan sayid atau mashäyikh lebih terbuka dalam

34 William G. Clarence Smith, "Hadhramaut and the Hadhrami in the Modern Colonial Era: An Introductory Survey", dalam Ulrike Freitag dan William G. Clerence Smith (eds.), Hadhrami Traders, Scholars, and Statesmen in Indian Ocean, 1750s1960s (Leiden: Brill, 1997), 1-8.

35 Ismail Fajrie Alatas, "Gold and Silver, Branded Horses, and Well-Tilled Land: Gender and Hadrami Migration”, Indonesia Feminist Journal, Vol. 3, No. 1 (2015), 413.

${ }^{36}$ Huub de Jonge dan Nico Kaptein, Transcending Borders Arabs, Politics, Trade, and Islam in Southeast Asia (Leiden: KITLV Press, 2002), 3.

37 Martin Slama, "Indonesian Hadhramis and the Hadhramaut: An Old Diaspora and Its New Connections", Jurnal_Antropologi Indonesia, Vol. 29, No. 2 (2005), 111 112. 
masalah perjodohan, sebagaimana yang dituturkan oleh Sugiharto (55) Kepala Desa Pulopancikan, "orang-orang Peranakan Arab dari kalangan bukan sayid ini agak longgar untuk persoalan perjodohan. Seperti saya ini, kan bukan Peranakan Arab. Istri saya adalah Peranakan Arab tapi bukan dari golongan sayid." 38

Pada beberapa kasus, berdasarkan observasi dan wawancara yang dilakukan peneliti, memang kafäab lebih dipegang oleh golongan sayid. Sementara tidak bagi golongan bukan sayid. Namun ada saja perempuan Peranakan Arab dari golongan sayid yang juga menikah dengan bukan sayid, ini dikuatkan dengan keterangan Umamah, "Kalau di keluarga saya, kafäah Alhamdulillah hingga saat ini masih dipegang, tidak ada anggota keluarga saya yang terutama perempuan yang menikah dengan bukan keturunan sayid. Tapi kalau secara umum di Gresik atau di Surabaya ada juga syarifah yang menikah dengan lelaki bukan dari Peranakan Arab. Apalagi di Jakarta, mungkin ini tergantung bagaimana pendidikan di keluarga". ${ }^{39}$ Kenyataan ini menjadi tantangan tersendiri bagi Peranakan Arab ketika arus kehidupan perkotaan yang bercorak modern di mana kebebasan dan keterbukaan menjadi ciri dari kehidupan sosial masyarakat kota.

Selain persoalan kafä'ah, aspek dalam kehidupan Peranakan Arab yang masih dirawat dan dijaga keasliannya adalah tradisi keagamaan. Meskipun faktanya, polarisasi paham keagamaan tidak bisa dielakkan pun terjadi di kalangan Peranakan Arab-Hadrami sendiri. Friksi mazhab keagamaan itu sudah banyak diungkap dalam beberapa penelitian seperti Syamsul Rijal (2017) dan Zulkifli (2013) yang menyebutkan bahwa terjadi polarisasi mazhab keagamaan di kalngan Peranakan Arab, yaitu antara Sunn̄̄ dan Shī'ah. Di kalangan Sunn̄̄ sendiri tidak bisa ditampik juga mengalami pecah kongsi sejak lama yang terbagi antara Rabitah Alawiyah dengan al-Irsyad. Rabithah corak keagamaannya lebih dekat dengan Nahdlatul Ulama (NU), serta al-Irsyad yang lebih dekat dengan Muhammadiyah. ${ }^{40}$ Rijal menyebut, bahwa pasca-revolusi Iran 1979, paham Shi'`ah mulai menginfiltrasi ke dalam kalangan Peranakan Arab di banyak negara termasuk di Indonesia. Hingga sekarang Shī‘ah juga menjadi bagian dari corak

\footnotetext{
38 Sugiharto (Kepala Desa Pulopancikan), Wawancara, Gresik 2 Juli 2018.

${ }^{39}$ Umamah, Wawancara, Gresik 4 Juni 2018.

40 Syamsul Rijal, "Internal Dynamics Within Hadhrami Arabs in Indonesia from Social Hierarchy to Islamic Doctrine", Journal of Indonesian Islam, Vol. 11, No. 1 (2017), 1-28, Zulkifli, The Struggle of the Shi'is in Indonesia (Canberra: ANU Press, 2013).
} 
keagamaan yang bisa ditemukan di dalam komunitas keturuanan Arab di Gresik terutama dari keturunan Sayid. Hal ini dipertegas oleh Taufiq Haris yang membenarkan kondisi kegamaan di kalangan Peranakan Arab, "infiltrasi paham Shī'ah di kalangan Arab itu terjadi ketika pengaruh Ayatullah Khomeini mulai masuk ke Indonesia sejak terjadinya Revolusi Iran. Pada waktu itu, bisa dikata $90 \%$ warga Peranakan Arab di Gresik sangat bersimpati dengan apa yang telah dilakukan oleh Khomeini. Memang ada beberapa orang dari Peranakan Arab yang hingga kini masih bermazhab Shī'ah namun tidak menampakkan secara terbuka. ${ }^{41}$

Berdasarkan hasil temuan dari penelitian ini, ritual keagamaan masih dipegang erat oleh sebagian besar warga Peranakan Arab di Gresik misalnya dalam hal pembacaan rätib, rawhah dan pembacaan selawat. ${ }^{42}$ Selain itu praktik keagamaan yang umum dilakukan di kalangan Peranakan Arab di Gresik lebih condong mengikuti mazhab Shāfiīiyah. Meskipun ada sebagian kecil yang sudah mulai terinfilterasi dengan paham-paham keagamaan lain. Seperti di Masjid Muhajirin yang memiliki kecenderungan mengikuti amaliah keagamaan al-Irsyad yaitu lebih condong menggambarkan Islam puritan. Berdasarkan pandangan dari Ahmad, salah satu tokoh muda Peranakan Arab dari golongan Sayid, bahwa pendidikan agama merupakan tonggak agar generasi Peranakan Arab ini agar selalu menjaga karakteristik ajaran para leluhurnya. Tidak boleh ada yang melenceng. Sebab menjaga ajaran agama sebagaimana para leluhur adalah tanggung jawab para keturunan sayid.

Sedangkan perubahan yang terjadi di kalangan muda Peranakan Arab terdapat pada beberapa aspek, diantaranya adalah masalah budaya. Bahwa tidak bisa ditampik pengaruh budaya global juga menyasar kalangan muda dari Peranakan Arab, misalkan saja pada cara berpakaian. Anak muda Peranakan Arab kebanyakan sudah terbuka terhadap perkembangan mode pakaian. Terutama bagi kelompok lakilaki. Dalam keseharian mereka, pakain yang dikenakan oleh Peranakan Arab tidak berbeda dengan umumnya masyarakat di Gresik. Anakanak muda yang laki-laki mengenakan jeans dan kaos. Sedangkan

\footnotetext{
41 Taufiq Haris (Sekretaris Yayasan Islam Malik Ibrahim (YIMI) yang mengurusi komplek Makam Sunan Malik Ibrahim, Wawancara, Gresik 24 Juni 2018.

42 Untuk lebih lengkapanya bisa melihat Fikri Mahzumi, "Telaah Sosio-Antropologis Praktik Tarekat 'Alawîyah di Gresik", Marâji: Jurnal Ilmu Keislaman, Vol. 1, No. 1 (2014), 67-80.
} 
orang-orang tua mengenakan sarung dan baju koko. Hanya pada momen-momen dan di kalangan tertentu saja para Peranakan Arab ini mengenakan jubah dan ikal. Selain budaya, pada aspek partikular bahasa merupakan perubahan yang mungkin bisa mewakili dari diskontinuitas Peranakan Arab dengan salafnya. Sekarang ini hanya Peranakan Arab yang masih terdidik di keluarga yang mempraktikkan bahasa Arab atau pernah mengenyam pendidikan di Hadramaut seperti di Universitas al-Ahqāe dan ribät-ribät di sana yang paham dan bisa berbicara dalam bahasa Arab.

\section{Catatan Akhir}

Peranakan Arab di Gresik terjadi pergulatan dwi identitas; antara menjaga tradisi Hadramaut yang telah lama diwariskan oleh leluhur mereka semenjak pertama kali datang ke Indonesia, dan menunjukkan rasa nasionalisme Indonesia yang merupakan kewajiban bagi setiap warga negara terhadap negaranya. Pergulatan ini berlangsung lama dan dinamis lebih-lebih ketika cita-cita Indonesia mulai tergambar dengan jelas ketika gerakan nasionalisme dan anti penjajah mulai tumbuh. Dilema identitas pun menyebabkan polarisasi di internal orang-orang Arab-Hadrami kala itu; antara yang menyerukan Hadramaut sebagai konsep wataniyah yang dimotori oleh Hadrami Totok dan kelompok Hadrami Peranakan yang menyeru Indonesia sebagai Tanah Air. Sampai kemudian A.R. Baswedan mendirikan PAI pada 1934 dan mendeklarasikan Sumpah Pemuda Keturunan Arab atas komitmen nasionalisme Indonesia. Dalam perkembangan selanjutnya, dwi identitas itu pun tidak serta-merta terselesaikan pasca-kemerdekaan, meskipun Peranakan Arab ini sudah diakui menjadi warga negara Indonesia. Justru persoalan dwi identitas ini menjadi rumit ketika isu-isu nasionalisme kembali diperbincangkan dewasa ini. Mereka pun dihadapkan pada tantangan menyejajarkan antara mewarisi tradisi Hadramaut dan menggelorakan kecintaan terhadap Tanah Air Indonesia. Dalam hal ini, sikap kompromitif, adaptif, dan inklusif sangat dibutuhkan.

Pada kasus dwi identitas ini, Peranakan Arab di Gresik bisa dibilang mampu memadukan dengan baik antara tanggung jawab mewarisi tradisi Hadramisme dengan tanggung jawab nasionalisme Indonesia. Pada beberapa aspek, Peranakan Arab di Gresik sudah sangat cair dengan warga Gresik dari etnis lain. Namun, pada beberapa aspek lain masih terlihat adanya eksklusivitas. Perkembangan 
pada Peranakan Arab terkini merupakan proses dari penyesuaian terhadap realitas kehidupan yang ada. Dalam beberapa aspek hidup, Peranakan Arab melakukan penyesuaian dengan tuntutan zaman. Seperti pada aspek politik, pendidikan, bahkan agama. Dari sinilah kemudian muncul kontinuitas dan diskontinuitas. Dalam praktik ibadah dan budaya, tradisi Hadramaut masih sangat dipegang erat oleh mayoritas keluarga Peranakan Arab seperti perihal kafäah dalam pernikahan. Tetapi pada sebagian kecil keluarga Peranakan Arab, kafä ah ini tidak lagi menjadi suatu keharusan. Sementara nasionalisme bagi Peranakan Arab di Gresik terwujud dari kontribusi mereka dalam bidang pendidikan, keagamaan dan penanaman cinta tanah air Indonesia bagi putra-putri mereka di sekolah dan keluarga.

\section{Daftar Rujukan}

Ahmad. Wawancara. Gresik 7 Juni 2018.

Alatas, Ismail Fajrie. "Becoming Indonesians: The Bā 'Alawī in the Interstices of the Nation", Die Welt des Islams, Vol. 51, 2011.

----. "Gold and Silver, Branded Horses, and Well-Tilled Land: Gender and Hadrami Migration", Indonesia Feminist Journal, Vol. 3, No. 1, 2015.

Algadri, Hamid. Islam dan Keturunan Arab. Bandung: Mizan, 1996.

Deliar Noer, The Modernist Muslim Movement in Indonesia, 1900-1942. Singapore: Oxford University Press, 1973.

Fatimah. Wawancara. Gresik 27 Juni 2018.

----. Wawancara. Gresik 4 Juni 2018.

Haikal, Husain. "Indonesia-Arab dalam Pergerakan Kemerdekaan Indonesia 1900-1942”. Tesis--Universitas Indonesia Jakarta, 1987.

Haris, Taufiq (Sekretaris Yayasan Islam Malik Ibrahim (YIMI) yang mengurusi komplek Makam Sunan Malik Ibrahim. Wawancara. Gresik 24 Juni 2018.

http://indopress.id (22 Juni 2018)

Jahroni, Jajang. "Menjadi Pribumi di Negeri Orang: Pergumulan Identitas Masyarakat Arab di Indonesia", Book Review--Natalie Mobini-Kesheh, The Hadrami Awakening: Community and Identity in the Netherlands East Indie: 1990-1942 (Ithaca: Southeast asian Program Cornell University, 1999), Studia Islamika, Vol. 7, No. 3, 2000.

Jonge, Huub de dan Kaptein, Nico. Transcending Borders Arabs, Politics, Trade, and Islam in Southeast Asia. Leiden: KITLV Press, 2002. 
Jonge, Huub de. "Abdul Rahman Baswedan and the Emancipation of the Hadramis in Indonesia", Asian Journal of Social Science, Vol. 32, No. 3, 2004.

"Discord and Solidarity among the Arabs in the Netherlands East Indie, 1900-1942”, Indonesia, Vol. 55, April 1993.

Kroef, Justus M. Van der. Indonesia in the Modern World. Part I. Bandung: Masa Baru, 1954.

Mahzumi, Fikri. "Telaah Sosio-Antropologis Praktik Tarekat 'Alawiyah di Gresik", Marâji: Jurnal Ilmu Keislaman, Vol. 1, No. 1, 2014.

Miftahuddin. "Dinamika Komunitas Diaspora Hadrami dalam Gerakan al-Irsyad di Indoensia 1945-2007. Disertasi-UIN Sunan Kalijaga Yogyakarta, 2017.

Mobini-Kesheh, N."The Arab Periodicals of the Netherlands East Indies, 1914-1942", Journal of Humanities and Social Sciences of Southeast Asia, Vol. 156, No. 2, 1996.

Patji, Abdul Rachman. "The Arabs of Surabaya: A Study of Sociocultural Integration". Tesis--Australian National University, 1991.

Qurtuby, Sumanto Al. "Arabs and 'Indo-Arabs' in Indonesia: Historical Dynamics, Social Relations and Contemporary Changes", International Journal of Asia Pacific Studies, Vol. 13, No. 2, 2017.

Rijal, Syamsul. "Internal Dynamics Within Hadhrami Arabs in Indonesia from Social Hierarchy to Islamic Doctrine", Journal of Indonesian Islam, Vol. 11, No. 1, 2017.

Slama, Martin. "Indonesian Hadhramis and the Hadhramaut: An Old Diaspora and Its New Connections", Jurnal Antropologi Indonesia, Vol. 29, No. 2, 2005.

Smith, William G. Clarence. "Hadhramaut and the Hadhrami in the Modern Colonial Era: An Introductory Survey", dalam Ulrike Freitag dan William G. Clerence Smith (eds.), Hadhrami Traders, Scholars, and Statesmen in Indian Ocean, 1750s-1960s. Leiden: Brill, 1997.

Sugiharto (Kepala Desa Pulopancikan). Wawancara. Gresik 2 Juli 2018. Suratmin dan Kwartanada, Didi. Biografi A.R. Baswedan: Membangun Bangsa Merajut Keindonesiaan. Jakarta: Penerbit Buku Kompas, 2014. 
Syahab, Yasmin Zaki. "Sistem Kekerabatan sebagai Katalisator Peran Ulama Keturunan Arab di Jakarta", Artikel dalam "Arab Society and Culture in Southeast Asia", Simposium Internasional Keempat Jurnal Antropologi Indonesia: "Indonesia in the Changing Global Context: Building Cooperation and Partnership?”, Universitas Indonesia, Depok, 12-15 Juli 2005. Umamah (Kepala SD Fatimiyah). Wawancara. Gresik 5 Mei 2018. Wawancara. Gresik 4 Juni 2018.

Zulkifli. The Struggle of the Shi'is in Indonesia. Canberra: ANU Press, 2013. 